Luiz Felippe P. Serpa* Ana

Cristina C. Lago**

\title{
A historicidade da historiografia
}

\section{INTRODUÇÃO}

SCHAFF, em seu livro História e Verdade coloca a questão fundamental, para a qual a resposta constitui-se no essencial da abordagem do texto.A questão fundamental é1:

À medida que os historiadores divergem, não têm a mesma visão do processo histórico, fornecemimagens diferentes, por vezes contraditórias, de umúnico acontecimento. Porquê?

$\mathrm{O}$ autor escolhe como exemplo a Revolução Francesa, por várias razões ${ }^{2}$

.... em primeiro lugar trata-se de um acontecimento to histórico

verdadeiramente importante. Em segundo lugar, há em relação a ele o recuo suficiente para evitar a alteração da percepção dos fatos pelas paixões. Em terceiro lugar, o acontecimento foi tal que influenciou não só os contemporâneos, mastambém as gerações seguintes, donde a variedade de atitudes a seu respeito da parte de historiadores vivendo em épocas diversas. Acontecimento afastado no tempo e simultaneamente importante, foi alvo de interesse de várias gerações de historiadores, o que permite confrontar as visões de um único fato em diversas épocas históricas.

SCHAFF limita o problema às causas da Revolução Francesa e, em particular, às suas causas económicas, bem como às obras de autores franceses. Com essa última limitação, segundo o autor ${ }^{3}$ :

Afastaremos um fator suplementar que intervém na diferenciação das atitudes dos historiadores e é imputável à diversidade dos patrimônios culturais, dos interesses nacionais, etc.

A seleção tem como critério a ordem cronológica, assim, são analisados Abade Barruel (1798), Joseph de Maistre (1796), Joseph Bamave (1793), Mme. de Stael (1818), Louis Blanc (1847), Laponneray (1838), Michelet (1847), Tocqueville (1857), Taine (1875), Jaurés (1901),Mathiez(1937), Léfèbvre(1957) e Labrousse (1944), totalizando treze obras, divididas em obras contemporâneas do acontecimento (quatro), intermediárias (cinco), e afastadas (quatro).

$\mathrm{Na}$ questão colocada, SCHAFF pre-ocupa-se com a dimensão da subjetividade do historiador ao abordar um acontecimento histórico. Dai, o autor ter escolhido um acontecimento - as causas económicas da Revolução Fran-cesa muito estudado por historiadores. A ordem cronológica e o conceito de afastamento temporal do historiador em relação ao acontecimento, como base de uma análise objetiva, demonstram a identifícação da história com a ordem temporal e a conceituação do espaço como um "a priori" absoluto.

Neste trabalho, pretendemos dar uma abordagem distinta à questão de SCHAFF. Primeiro, consideraremos o espaço-tempo determinado por uma teia de relações de desenvolvimentos desiguais, cada uma contendo a contradição, como definidor de sua historicidade *. Assim, as obras que constituem a historiografia expressarão o movimento da teia de relações em que os próprios historiadores estão imersos. Em conse-quência, a diversidade de interpretações emerge da historicidade do historiador e da historiografia.

A subjetividade do historiador é a expressão da objetividade da História, definida pela imersão do historiador na teia de relações que determina a historicidade do espaço-tempo.

Para desenvolvermos esta aborda- gem, apresentaremos a seguir a 
, ' sistematização das diferentes obras e seus diferentes núcleos interpretativos. Em seguida, elaboraremos os padrões das relações interpretativas, expressan-do as diferentes teias de relações definidoras do espaço-tempo. Finalmente, através de uma análise desses padrões, procuraremos mostrar a historicidade da historiografia, ratifican-do que a subjetividade do historiador é a expressão da objetividade da História.

\section{A SISTEMATIZAÇÃO DAS OBRAS}

As diferentes interpretações podem ser distribuídas no espaço e no tempo em torno de três núcleos interpretativos: Concepção Teleológica, Pobreza do Povo e Conflitos de Classe.

No núcleo Concepção Teleológica, encontram-se dois historiadores na fase contemporânea, um na fase intermediá-ria e nenhum na fase afastada do acontecimento.

No núcleo Pobreza do Povo, encon-, tram-se um historiador na fase contemporânea, três na fase intermedi-ária e um na fase afastada do acontecimento.

Por sua vez, no núcleo Conflito de Classe, encontram-se um historiador na fase contemporânea, um na fase intermediária e três na fase afastada do acontecimento.

Como o estudo é baseado no livro de SCHAFF. restringimo-nos aos historiadores considerados pelo autor, todos de origem francesa. É claro que, segundo nossa concepção, a consideração de historiadores de outras nacionalidades traria uma maior diversidade, pois a pluralidade de interpretações expressa-ria mais claramente a objetividade da História, isto é, explicitaria melhor a imersão dos historiadores no espaço-tempo histórico. A historicidade dos historiadores e da historiografia seria mais manifesta.

A sistematização das obras consideradas neste estudo encontra-se a seguir, onde, a partir de SCHAFF, apresentam-se os núcleos interpretativos e as fases, as quais se referem aos diferentes histo-riadores, em fases distintas do mesmo núcleo interpretativo (quadro 1).

\section{O ESPAÇO-TEMPO DOS PA-DRÕES DE INTERPRETAÇÃO}

A partir da sistematização, podemos formar padrões de teias de relações interpretativas, onde cada núcleo explicita um atrator do padrão.

A) Núcleo Concepção Teleológica:

Esse núcleo apresenta dois historiadores na fase contemporânea, um na fase intermediária e nenhum na fase afastada. A característica teleológica justificase por explicações que apontam uma finalidade "a priori" (Deus ou conspiração intencional).

Da fase contemporânea, extraímos uma síntese das explicações dos historiadores:

Abade Barruel(1798):Arevoluçãofoi o resultado de uma conspiração internacional dos jacobinos, com a participação de Voltaire, Diderote... o Rei Frederico." Nesta revolução, tudo, até os crimes mais horríveis, tudo foi previsto, meditado e conduzido por homens que eram os únicos a conhecer o fio das conspirações durante muito tempo em sociedades secretas".

Joseph de Maistre (1796): A Revolução Francesa tem como única causa a vontade de Deus. "Mas nunca a ordem é mais visível, nunca a providência é mais palpável do que quando a sua ação superior se substitui ã do homem e age sozinha; é o que vemos neste momento".

Da mesma forma, na fase intermedi-ária, Louis Blanc (1847) consagra a influência da Franco-maçonaria na revolução. "Em um tom objetvo, o autor procura demonstrar que a revolução foi a obra de uma conspiração urdida por uma organização secreta. Descrevendo pormenorizadamente 0 mecanismo desta organização, em par-ticular dos "iluministas".

A fase afastada não apresenta historiador nesse núcleo interpretativo.

B) Núcleo Conflitos de Classe:

Esse núcleo tem um historiador na fase contemporânea, um na fase intermediária e três na fase afastada. 
Eis as sínteses explicativas dos referidos historiadores.

- Fase contemporânea:

Joseph Bamave (1793): A Revolução Francesa deve ser analisada no contexto da evolução dos sistemas da Europa desse tempo. Para ele, foram três os motivos da Revolução: a transformação das relações entre as classes sociais, processo que se verificou em toda a Europa; a fraqueza do poder monárquico; a popularização das ideias de revolução e liberdade, repercutidas pela guerra entre a América e a metrópole, que contou como apoio político da França.

- Fase intermediária:

Laponneray (1838). As causas da revolução encontram-se no processo histórico e no progresso das idéias, bem como nas contradições entre as classes da sociedade francesa, onde o conflito era baseado concretamente na exploração:

"A nação francesa dividia-se em duas classes, uma exploradora e a outra explorada, ou melhor dizendo, a classe explorada era constituída pelo $3^{\circ}$ Estado e pela multidão e ela só formava a nação, porque a classe exploradora era apenas uma minoria imperceptível (que tinha todos os pri- vilégios, enquanto o povo tinha apenas impostos e serviços). As coi-sas estavam neste ponto quando surgiu, como um astro brilhante no meio da uma noite profunda, a Filosofia do Século XVIII, filha da reforma religiosa. Empreendeu-se então um enorme trabalho de idéias, não só na França, mas em toda a Europa. Os espíritos fermentavam prodigiosamente. (...) Tomou-se inevitável uma revolução". - Fase Afastada:

Jaurès (1901). A causa da Revolução Francesa foi o reforço do poder do $3^{\circ}$ Estado em consequência de um rápido desenvolvimento económico. "Para que rebente uma revolução, é necessário que as classes inferiores sofram de um terrível mal-estar. Mas é necessário também que tenham um princípio de força. A opressão das classes não é condição suficiente". Apesar dos rigores do fisco, existiam poupanças suficientes nos campos, e esperança de liberdade de se comprar pedaços de terras eclesiásticas. A causa principal da Revolução Francesa foi o crescimento da força da burguesia, que aspirava apo-derar-se do poder Neste ponto, Jaurès acredita no papel revolucionário da ideologia, não a filosofia das luzes, mas a que tira sua força do fato de se constituir num instrumento de consciência de classe. O poder da burguesia provinha da atividade industrial, comercial e financeira; ameaçada pelo espectro da falência financeira do estado, ela procurava uma nova ordem social, capaz de garantir seus direitos.

Mathiez (1937) coloca que a causa da revolução é o conflito ideológico entre a aristocracia e a burguesia, pois esta últi-ma tinha posse do dinheiro e queria também o poder morai. Os intelectuais que tomaram partido pelas transformações da ordem social, puseram-se a trabalhar no sentido de despertar a 
consciência revolucionária entre as massas populares, a serviço da causa da classe ascendente. $\mathrm{O}$ autor menciona a crise económica, o desemprego, as más colheitas (1788), e o aumento do preço do pão como fatores do contexto pré-revolucionário; porém sem enfraquecer o efeito da prosperidade.

Léfèbvre (1957): A causa da revolução não foi a miséria, mas as lutas de classe, em relação com o desenvolvimento económico. E a classe rural também se beneficiou do crescimento económico, apesar de estar mais sobrecarregada de impostos e obriga-ções que qualquer outra classe. Os únicos que sofreram com a situação económica foram os proletários, que além de serem objetos de discriminações econô-micas, eram privados de consciência de ciasse. O crescimento económico pro-moveu o aumento do poder de novas classes (a burguesia), o que gerou conflitos entre esta e as classes já instaladas no poder(realeza e aristocracia). Segundo Léfèbvre, toda esta situação gerou "uma guerra entre o $3^{\circ}$ Estado e as duas ordens" que teve como causa direta da "explosão revolucinonária" a alta exorbitante do preço do pão e o grave desemprego.

C) Núcleo Pobreza do Povo:

Esse núcleo tem um historiador na fase contemporânea, três na fase intermediária e um na fase afastada.

Eis as sínteses explicativas dos referidos historiadores:

Fase Contemporânea:

Mme.deSTAEL(1818):Acausa profunda da revolução resulta da mudança de situação da burguesia. Mas a revolu-ção foi provocada não só pela transformação de posição da nova ciasse, mas também pela miséria do camponês, ã qual se juntava a arbitrariedade do poder.

"Os impostos que incidiram exclusivamente sobre o povo reduziram-no à pobreza sem esperança". "Os jovens e estrangeiros que não conheceram a Franca antes da revolução (...) não podem imaginara situação deste país quando a nação suportava o preço de todos os privilégios". "A miséria aumenta a ignorância e a ignorância aumenta a miséria; e quando nos perguntamos por que razão o povo francês foi tão cruel durante a revolução, não podemos encontrar resposta senão na ausência de felicidade, que conduz à ausência de moralidade".

Fase Intermediária:

MICHELET (1847): As causas da Revolução Francesa são múltiplas: (a)a influência da ideologia, em particular das idéias de Voltaire e Rousseau; (b) a desordem financeira do estado-a falên-da total como consequiência da pilhagem do tesouro pelos poderosos, aos quais o rei não sabia resistir (c) a arbitrariedade do poder real levantou a opinião pública contra a monarquia; (d)admadetudo,a causa fundamental da revolução foi a miséria. "A miséria é um fato tão geral

(...) que os historiadores raramente reparam nela". "A sociedade france-sa está organizada para produzir cada vez menos e pagar cada vez mais... Desde Luís XIV, as taxas são tão pesadas, que em Maules, em Etanpes e em outros lugares, se arrancaram todas as vinhas". "Não tendo camponês móveis para serem confiscados, o fisco não tem outro objeto de penhora que não seja o gado; extermina-o pouco a pouco. A cultura dos cereais, desenvolvida no século XVII por imensos arroceamentos, restringe-se noséculoXVIII(...) em muitos sítios;já não vale a pena cultivar".

TOCQUEVILLE (1875). A causa primeira da revolução francesa estava nas dificuldades financeiras do governo em relação a um déficit orçamental crescente. $\mathrm{O}$ estado estava à beira de uma falência que ameaçava os "direitos sagrados" de seus credores (os capitalistas), que normalmente formam uma classe inimiga das novidades políticas, mas desta vez mostraram-se impacien-tes e os mais resolutos em matéria de reforma em todo o sistema financeiro, sem pensar que mexendo profunda-mente nesta parte do governo, iria fazer cair todo o resto. A Revolução Francesa teve por causa principal não a miséria, mas, pelo contrário, o desenvolvimento económico do país (desenvolvimento em que a classe rural também se bene-ficiou). Este desenvolvimento levou à revolução, e "devia conduzir à abolição do feudalismo. A tendência anti feudal era geral na Europa,mas a situação na França era mais confortável do que em outros países, 
pois o senhor feudal tinha perdido os privi-légios administrativos e seus direitos eram cada vez mais limitados pelo rei". Tocqueville acreditava que a causa da Revolução Francesa era exa-tamente esta: "Apesar de todas as dificuldades enfrentadas no período, a situação da França não era a pior, porém o povo estava sensibilizado, pois seu jugo pareceu mais insuportável onde era na realidade mais leve".

TAINE (1875) retoma o tema da miséria, em particular a miséria do camponês, como causa da Revolução Francesa. Taine utiliza o mesmo contexto tocado por Tocqueville, porém lhe dá uma outra abordagem. Ele acredita que o camponês proprietário é mais sensível ao peso dos impostos e das obrigações, do que o camponês que trabalha em terras senhoriais. E se a classe camponesa possuía terras antes da revolução, isto se deu em função da ruína da nobreza e da abnegação do camponês, que nada retirava delas, apesar dos sacrifícios consentidos: "Quando o homem é miserável, irrita-se; mas quando é simultaneamente proprietário e miserável, irrita-se mais ainda".

Fase Afastada:

LABROUSSE (1944) analisa as causas da revolução a partir de duas questões: o movimento dos preços e rendimentos, e a crise econômica nas vésperas da revolução. As questões estão diretamen-te ligadas ã alta brusca dos preços e as suas influências sobre o rebaixamento do nível de vida da população. "E certo que os rendimentos de uns aumentam, e os de outros decrescem; o desemprego se alastra. Já não se trata portanto de prosperidade, mas, pelo contrário, de miséria das classes populares". Labrousse não nega a rápida expansão da economia francesa no contexto da alta dos preços dos produtos agrícolas; mas em 1788 nota-se uma queda de preços destes produtos, que gera uma crise cíclica: O desemprego aumenta, os demais preços não param de subir, poucos prosperam, e muitos empobrecem. A crise financeira é uma causa direta do agravamento da regressão econômica; no geral, é a miséria das classes popula-res que dá origem à explosão revolucionária.

\section{ANÁLISE DOS PADRÕES}

Os diagramas representativos dos padrões interpretativos e da dinâmica dos atratores dos padrões expressam dará-mente a historicidade dos historiadores e de suas obras.

No diagrama 1, os atratores do padrão são disjuntos, ou seja, não há relações comuns ou semelhantes nos contornos de cada teia de relações. Isso significa

que, na contemporaneidade da Revolução Francesa, a teia de relações determinante do espaço-tempo histórico expressava um momento de transformação: de um lado, os Estados dominantes (clero e nobreza), e de outro, o terceiro Estado. No segmento do terceiro Estado, emergem duas variedades: a burguesia e o povo.

No diagrama 2, mantêm-se os mesmos atratores dos padrões, o que demonstra a permanência do poder do clero e da nobreza, ao mesmo tempo em que se notam relações comuns nos atratores Pobreza do Povo e Conflitos de Classe, tais como ideologia-Progresso das Idéias e Miséria-Exploração.

O diagrama 3 demonstra a afirmação histórica da burguesia e da sociedade moderna, pois o atrator _Concepção Teleológica desaparece do padrão representativo das interpretações. Dominam os atratores Conflitos de Classe e Pobreza do Povo, com relações comuns nos contornos das respectivas teias de relações.

Assim, o padrão interpretativo do diagrama 3 expressa o poder hegemónico da sociedade moderna burguesa e o declínio definitivo da sociedade feudal.

É na dinâmica dos atratores (diagra-mas4,5 e 6) que se observa o movimento dos padrões, ratificando a dinâmica da teia de relações determinante do espaçotempo histórico. Nos diagramas 5 e 6, os atratores correspondentes mantêm sua dinâmica, enquanto no diagrama 4 desaparece o atrator de natureza teleológica na fase afastada.

A intensidade das teias de relações de cada atrator é representada no quadro 2.

O gráfico apresenta o peso relativo de cada atrator nos padrões interpretativos de cada fase, e, portanto, a dinâmica das teias de relações determinantes do espa-çotempo histórico em cada momento, expressando o declínio da sociedade feu-dal 
e a afirmação histórica da sociedade moderna.

\section{CONCLUSÃO}

Pensamos que a análise realizada dos padrões ínterpretativos põe em evidência que a subjetividade do historiador e os diferentes núcleos interpretativos de um acontecimento \{ constantes da historiografia) são a expressão da objetividade da História; mais do que isso, explícita a História como o substrato fundamental de qualquer conhecimento.

As variações interpretativas dos historiadores, em um mesmo momento, são determinadas pela historicidade do historiador, isto é, pela teia de relações definidora da imersão do historiador na totalidade da teia de relações que deter-

mina o espaço-tempo histórico, no momento respectivo.

A variação interpretativa de historiadores em momentos distintos expressa o movimento da totalidade da teia de relações que determina o espaço-tempo histórico, bem como as diferentes teias de relações definidoras da imersão do historiador na teia de relações fundamental.

Assim, diferentemente de SCHAFF, não consideramos a verdade como um limite de verdades parciais. Ao contrário, a verdade é histórica. Ao mesmo tempo, não consideramos que a subjetividade da interpretação dos historiadores é um indicador da subjetividade da história. Ao contrário, expressa a objetividade do absoluto matéria-movimento, gênese da história, substrato.

\section{NOTAS}

(1) SCHAFF, Adam, História e Verdade, trad. Maria Paula Duarte, rev. Carlos Roberto F. Nogueira, $3^{\text {a }}$ ed., São Paulo: Martins Fontes, 1986 ( Série Novas Direções),p. 10.

(2)ibid.p. 10.

(3) Ibid. p. 11.

(4)SERPA, L.F.P., Ciência e Historicidade. Multipress, Salvador, edição do autor, 1991.

QUADRO 1
\begin{tabular}{|l|c|l|l|}
\hline $\begin{array}{l}\text { NÚCLEO } \\
\text { INTERPRETATIVO }\end{array}$ & $\begin{array}{l}\text { FASE/ } \\
\text { CONTEMPORÂNEO }\end{array}$ & \multicolumn{1}{|c|}{$\begin{array}{l}\text { AFASTADO } \\
\text { INTERMEDIÁRIO }\end{array}$} \\
\hline $\begin{array}{l}\text { CONCEPČO } \\
\text { TECNOLÓGICA }\end{array}$ & $\begin{array}{l}\text { ABADE BARRUEL-1798 } \\
\text { JOSEPH DE MAISTRE -1796 }\end{array}$ & LOUIS BLANC-1847 & \\
\hline $\begin{array}{l}\text { CONFLITOS } \\
\text { DE CLASSE }\end{array}$ & JOSEPHBARNAVE-1793 & LAPONNERAY-1838 & $\begin{array}{l}\text { i JAURES-1902 } \\
\text { MATHIEZ-1937 } \\
\text { LEFEBVRE -1957 }\end{array}$ \\
\hline $\begin{array}{l}\text { POBREZA } \\
\text { DO POVO }\end{array}$ & MME. DE STAEL-1818 & $\begin{array}{l}\text { NICKELET-1847 } \\
\text { TOCQUEVILLE-1875 } \\
\text { TAINE-1875 }\end{array}$ & LABROUSSE-1947 \\
& & & \\
\hline
\end{tabular}




\section{QUADRO 2}

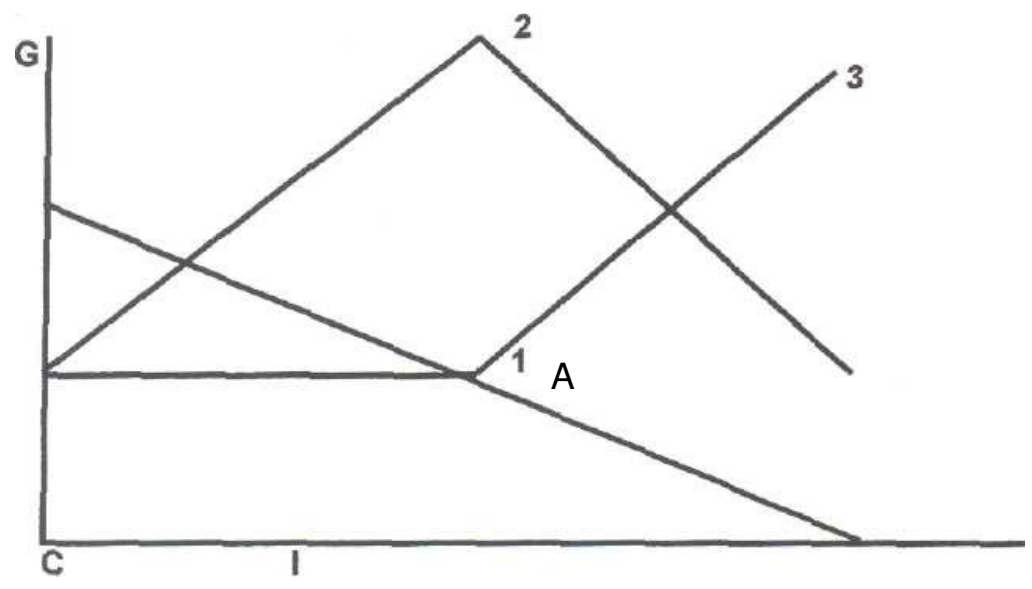

G- Grau relativo

X- Distância do acontecimento

C- Contemporâneo

I- Intermediário

A- Afastado

1- Concepção teleológica

2- Pobreza do povo

3- Conflitos de classe 
PADRÃo CONTEMPORÂNEO AO ACONTECIMENTO
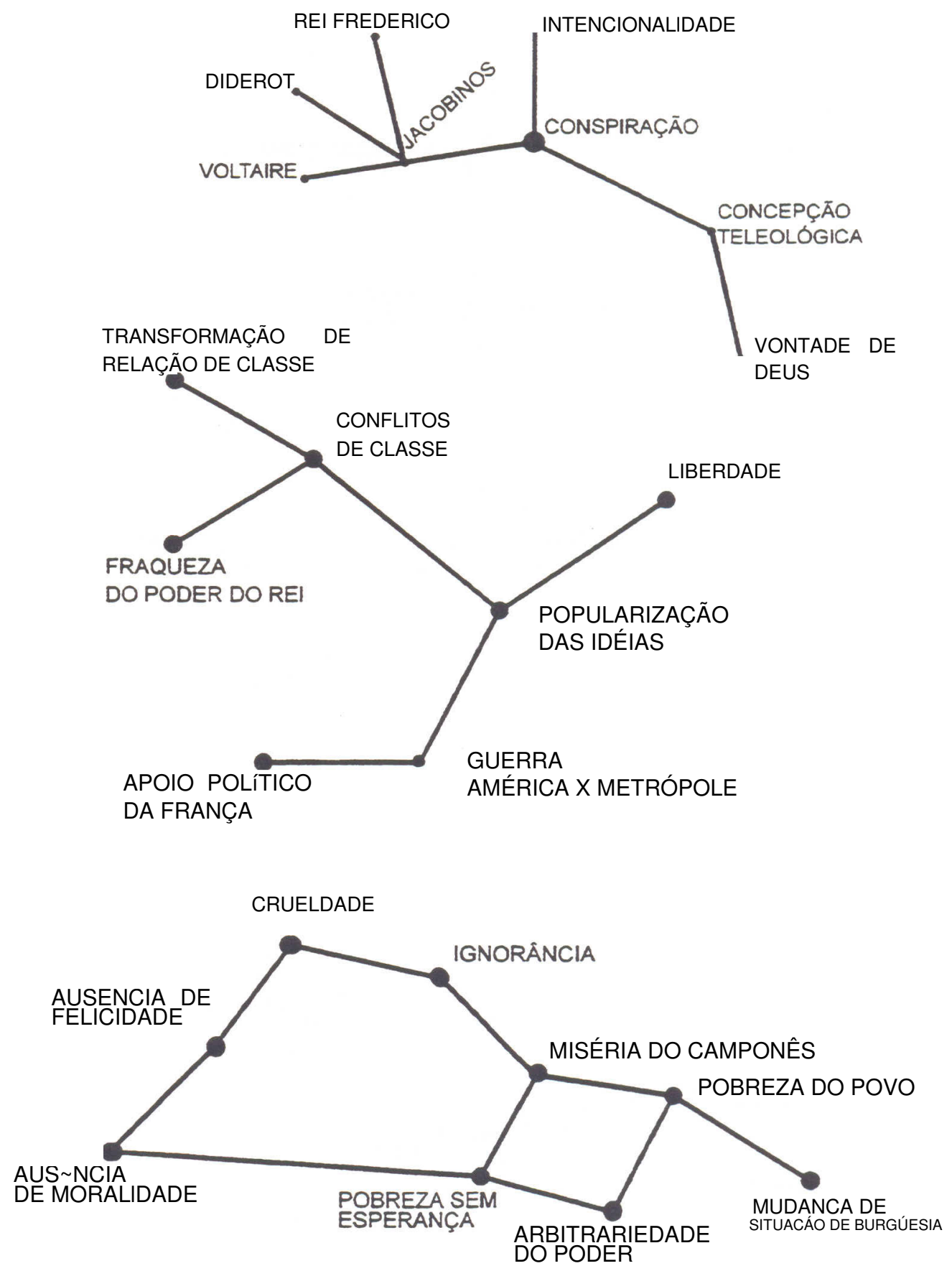
DIAGRAMA2

PADRÃo INTERMEDIÁRIO AO ACONTECIMENTO
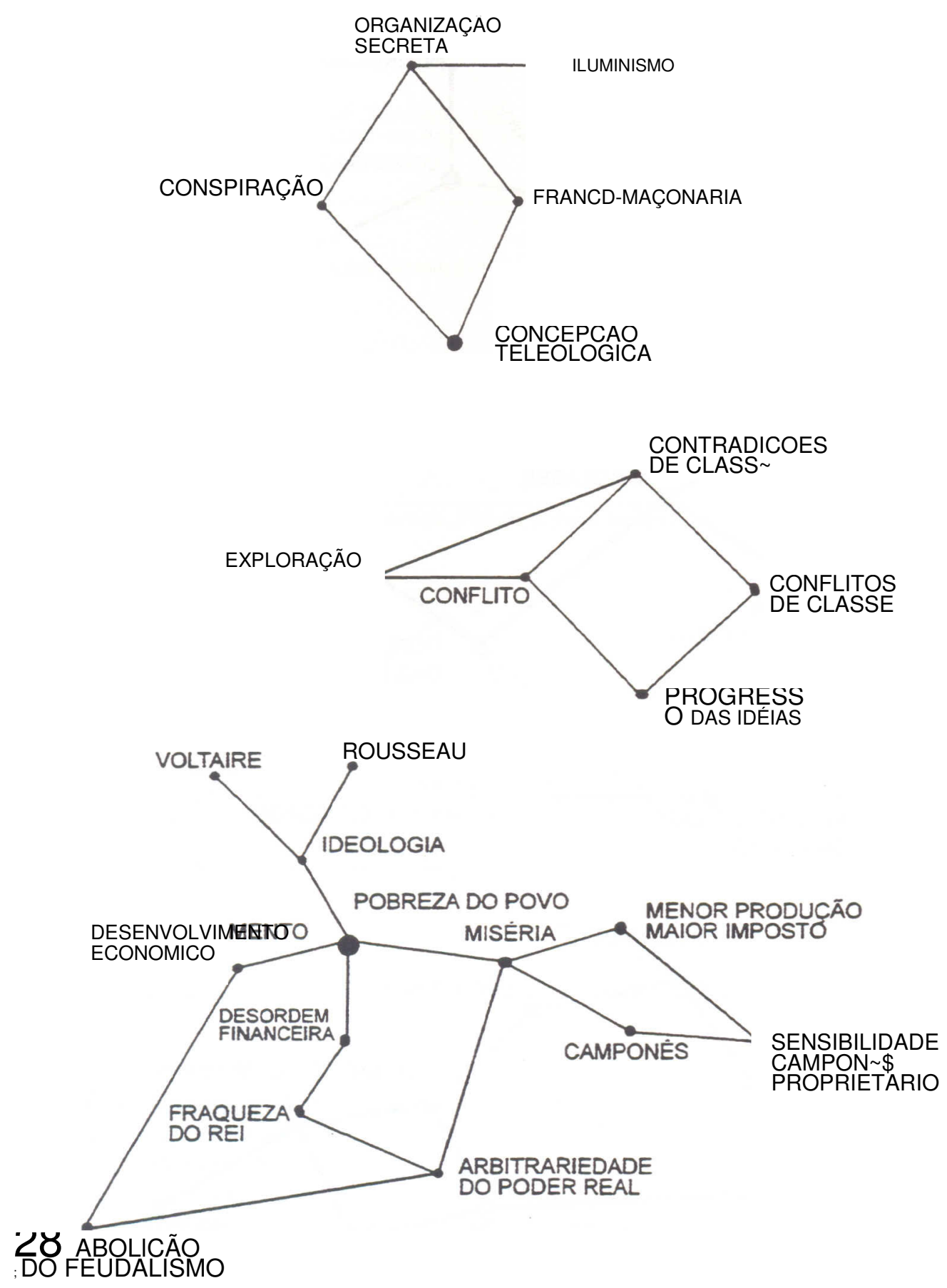

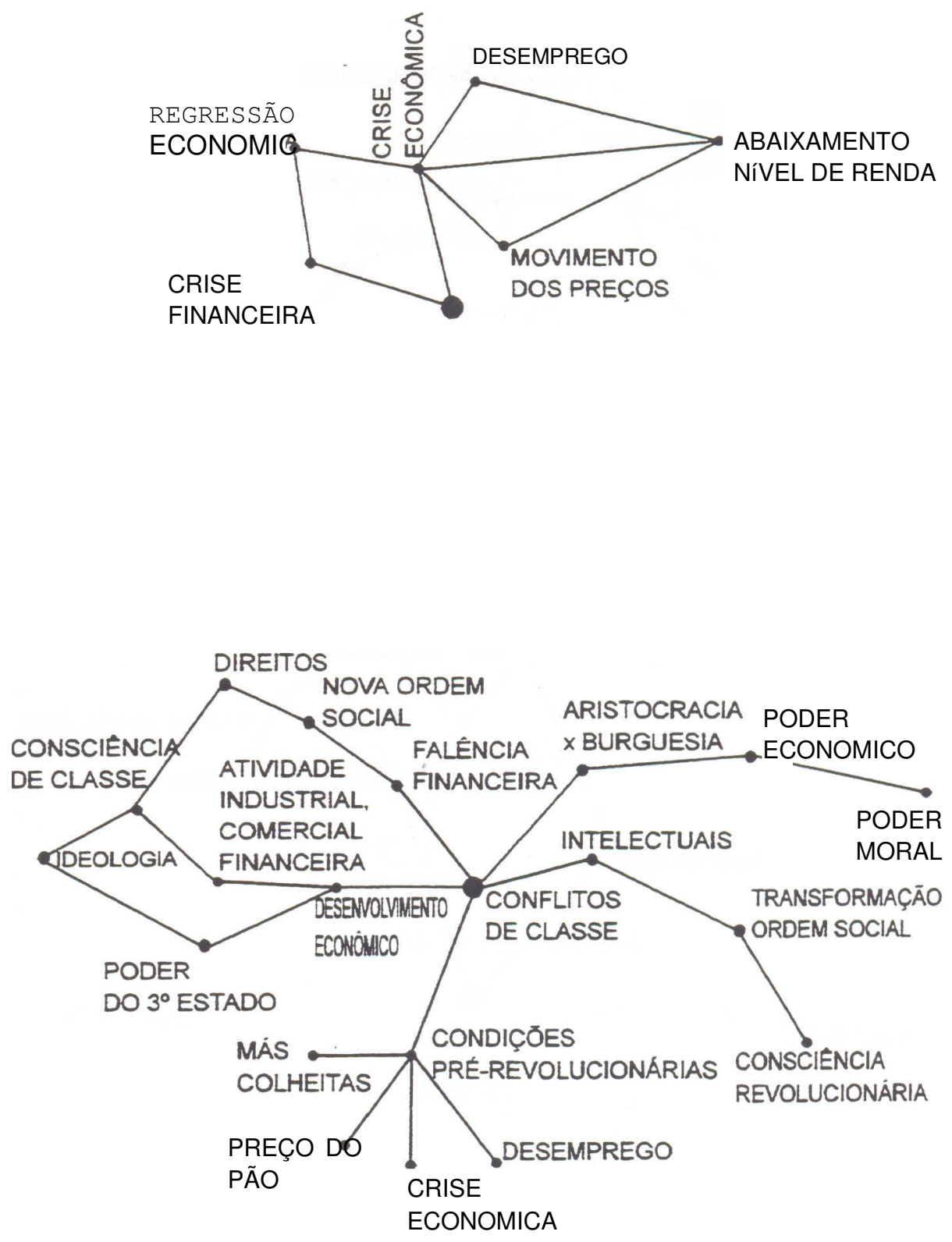


\section{DIAGRAMA4}

DINÂMICADOATRATORCONCEPÇÃOTELEO ÓGICA

\section{CONTEMPORÂNEO}

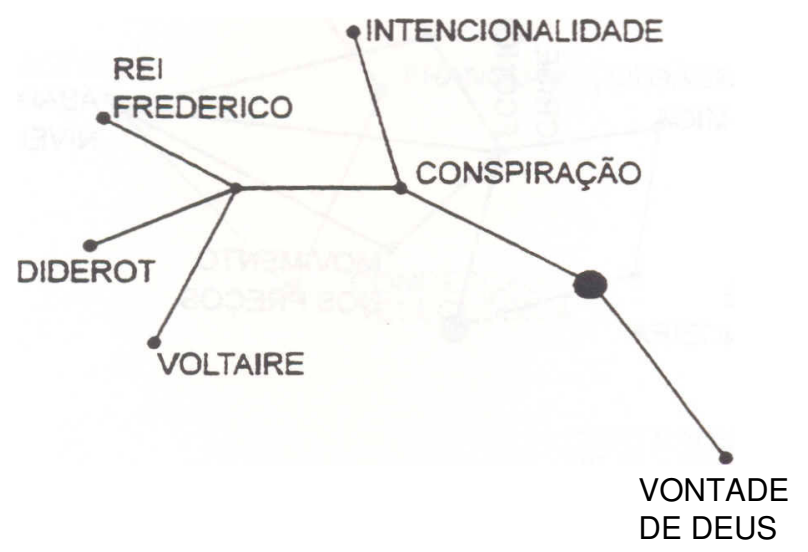

INTERMEDIÁRIO

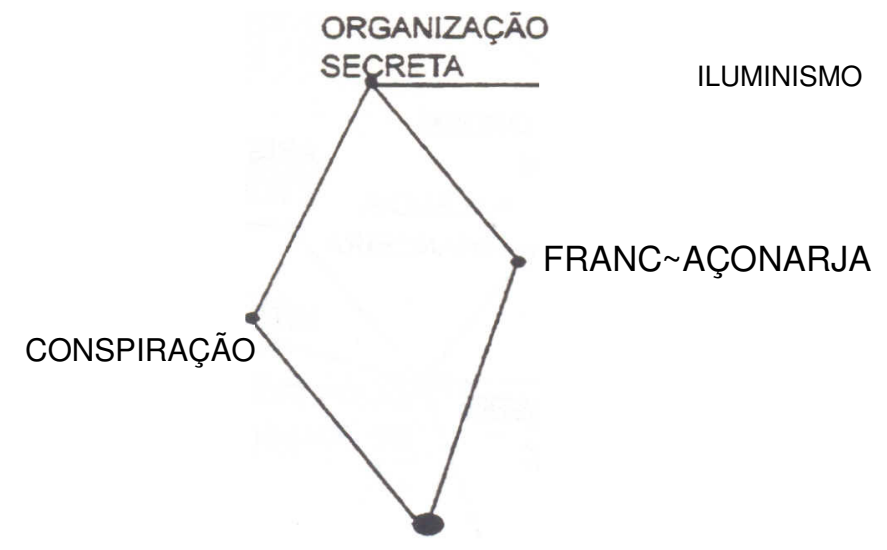

AFI $>5 T A O O$ 
DIAGRAMA5

DINÂMICA DO ATRATOR POBREZA DO POVO

CONTEMPORÂNEO

MUDANÇA DA

SITUAÇAO

DA BURGUESIA
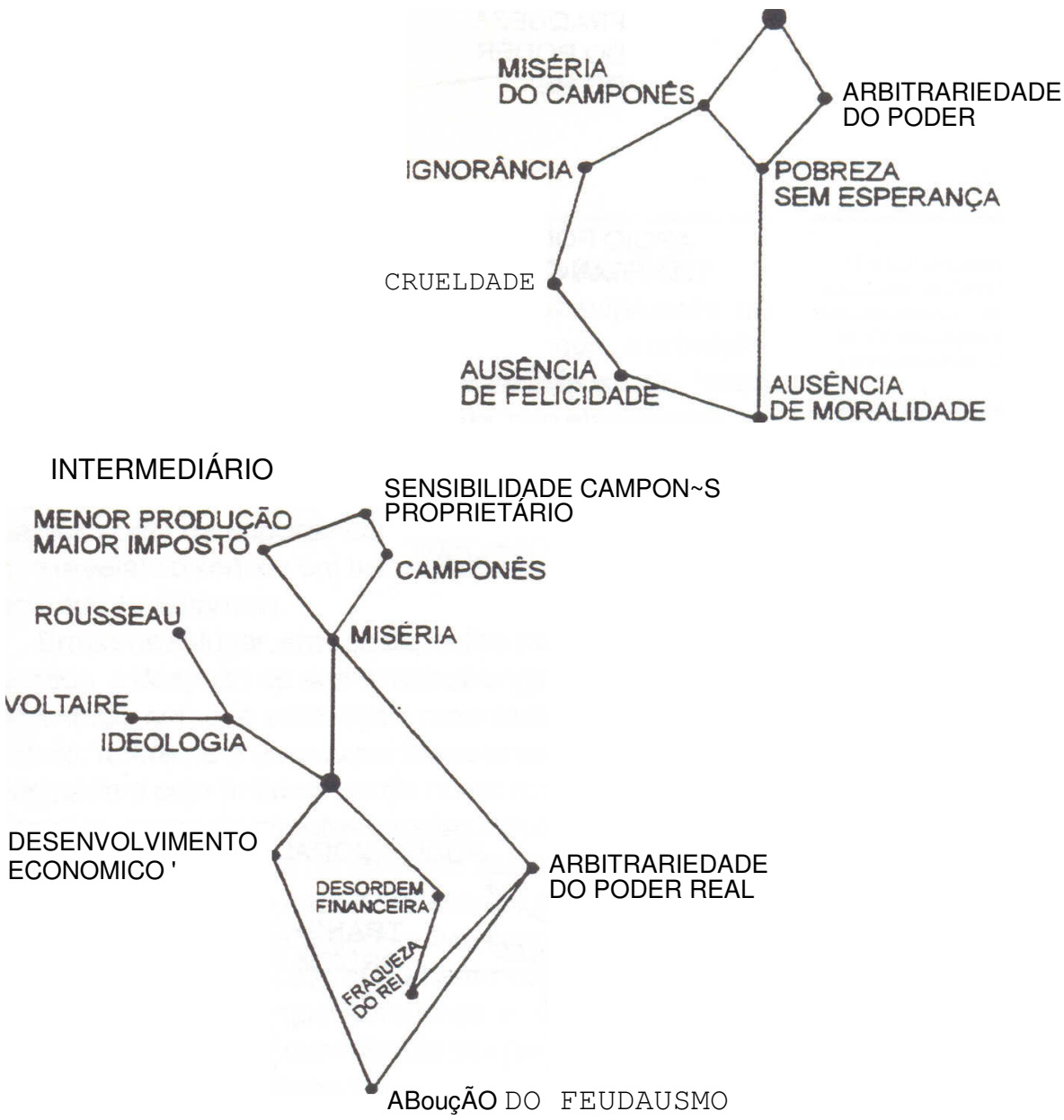

AFI>STAOO

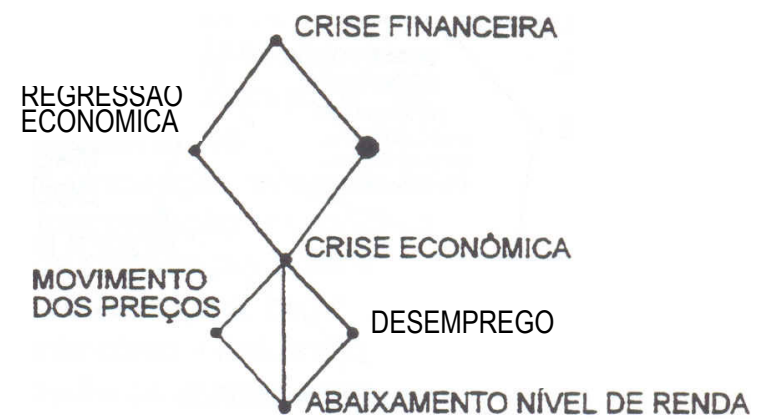




\section{DIAGRAMA6}

DINÂMICA DO ATRATOR CONFUTOS DE CLASSE

CONTEMPORÂNEO

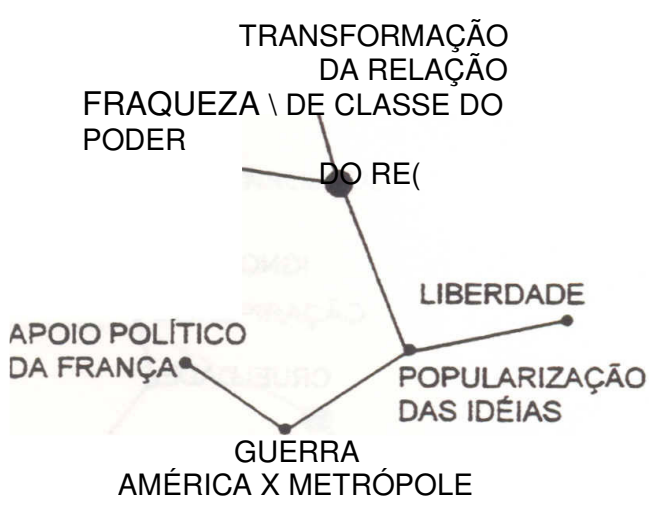

INTERMEDIÁRIO

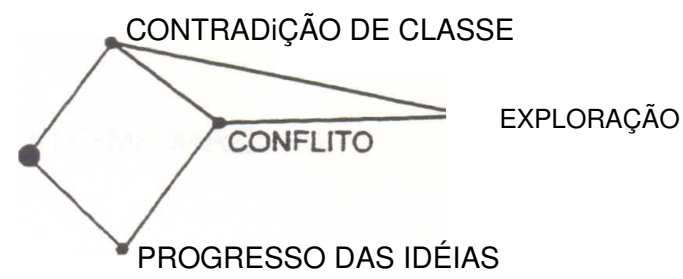

AFPSr/IOO

PODER MORAL

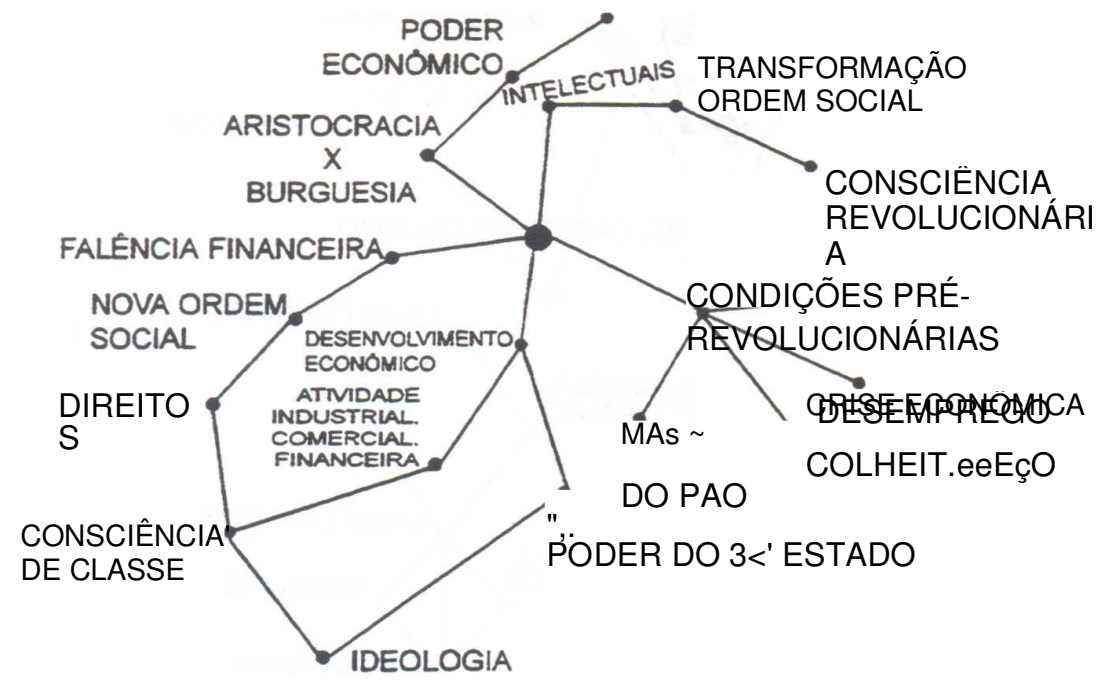

